\title{
PDCA Cycle and Six Thinking Hats in the Teaching Reform of Modern Machining Technology
}

\author{
JiCai KUAI ${ }^{1, a^{*}}$ \\ ${ }^{1}$ School of Mechanical and Power Engineering, Henan Polytechnic University, \\ Jiaozuo 454000, China \\ ahitgjc@163.com \\ ${ }^{*}$ corresponding author
}

Keywords: Modern Machining Technology; PDCA cycle; Six Thinking Hats; Quality management; Teaching reform.

\begin{abstract}
To improve teaching quality, this paper proposes advanced quality management method, which means to use PDCA cycle and Six Thinking Hats to conduct the teaching reform of "Modern Machining Technology". It also analyzes teaching problems existing in the "Modern Machining Technology" and those factors that affect the teaching quality, combines PDCA cycle and Six Thinking Hats and the teaching of "Modern Machining Technology", and takes a series of improvement measures to improve teaching quality gradually, provide a new scientific method for teaching reforms, which has important theoretical significance and practical value for the teaching reform work.
\end{abstract}

\section{Introduction}

"Modern Machining Technology" is a comprehensive systematic technology. It is also the generic term of advanced technology which can adapt to future manufacturing generated by the combination of the latest achievements, theories, methods in traditional manufacturing technology, basic science, management, humanities and sociology, as well as engineering technology etc. It is a kind of emerging cross-discipline integrating mechanic, electronic, information, materials and management [1].

Based on previous research, this paper conducts analysis and summary on all the teaching links of Modern Machining Technology, and applies PDCA cycle and Six Thinking Hats approach into Modern Machining Technology teaching, for the purpose of providing a new and practical method for the teaching reform.

\section{Principle of PDCA cycle [2-5]}

PDCA Cycle. PDCA cycle includes four phases, shown as Fig.1. That is, Plan, Do, Check, Action.

Stage Plan. 1) Carefully analyze the problems existing in teaching links, and conduct summary as well as classification; 2) Analyze the influencing factors of problems existing in teaching links, that is, Man, Machine, Materials, Method, Environment(4M1E);

Man: Whether there exis factors that influence teaching quality in teachers themselves in the subjective aspect;

Machine: Analyze whether there exists factors that affect teaching quality of equipment in multi-media classroom;

Materials: whether the courseware itself is perfect and whether it can take full advantage of multimedia capabilities;

Methods: there are shortages in teaching methods;

Envrionment: the impact of surrounding environment on the teaching quality; whether there are environmental factors that affect the teaching quality; 
3) Analyze the main factors; In the above analysis, find the main factors as the problem to be solved in this PDCA cycle;

4) Against the main factors, make solutions to meet the $5 \mathrm{~W} 1 \mathrm{H}$;

1W(Why): Why we should make such a plan? 2W(What): What goal we should achieve? 3W(Where): Where it should be performed? 4W(Who): Who completes? 5W(When): What time? $1 \mathrm{H}(\mathrm{How})$ : How to complete?

Stage Do. Conscientiously implement the plan made in stage P.

Stage Check. conduct inspection on the implementation condition and effect in stage D.

Stage Action. conduct the summary on the experience and issues of PDCA cycle, gain experience, and bring new found problems as well as those to be solved in the next PDCA cycle, for the purpose of improving the teaching quality gradually, as shown in Fig.2.
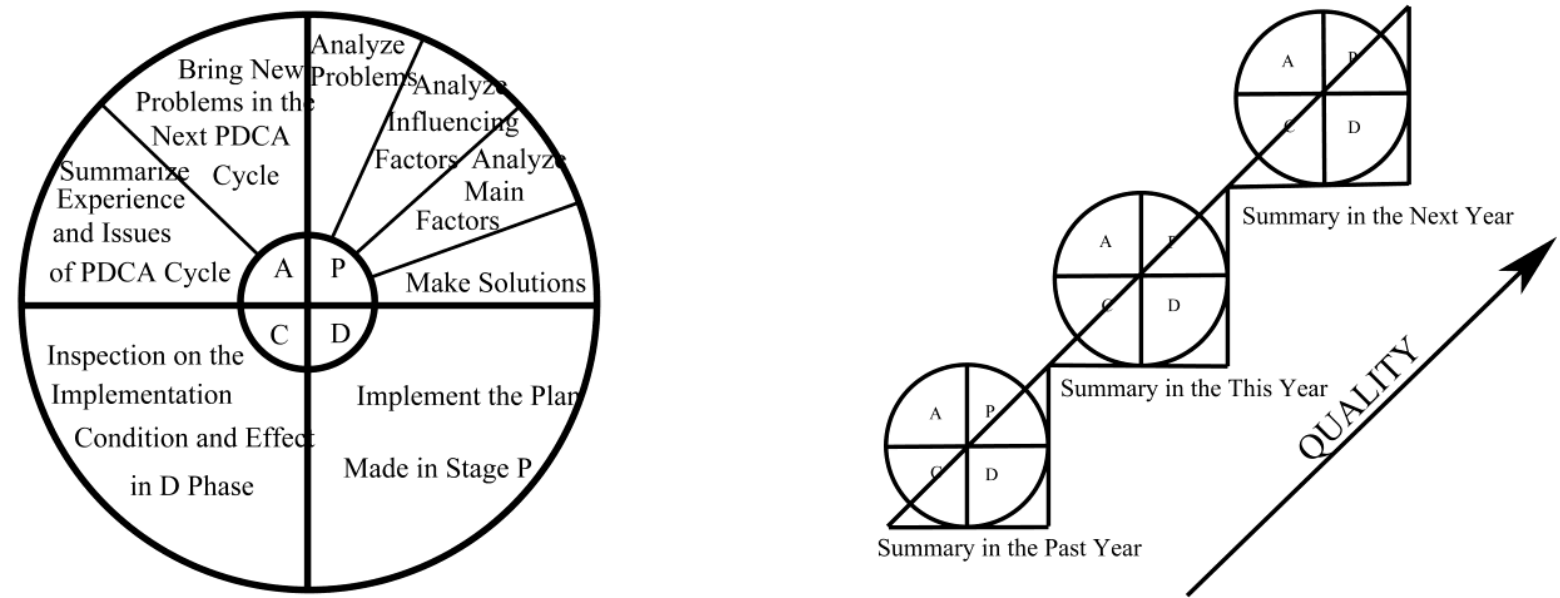

Figure. 1 Principle of PDCA cycle Figure. 2 Quality improvement after application of PDCA cycle

\section{The Six Thinking Hats[6-10]}

Six Thinking Hats is a book by Edward de Bono which describes a tool for group discussion and individual thinking involving six colored hats. "Six Thinking Hats" and the associated idea parallel thinking provide a means for groups to plan thinking processes in a detailed and cohesive way, and in doing so to think together more effectively.

The premise of the method is that the human brain thinks in a number of distinct ways which can be deliberately challenged, and hence planned for use in a structured way allowing one to develop tactics for thinking about particular issues. de Bono identifies six distinct directions in which the brain can be challenged. In each of these directions the brain will identify and bring into conscious thought certain aspects of issues being considered (e.g. gut instinct, pessimistic judgement, neutral facts). None of these directions are completely natural ways of thinking, but rather how some of us already represent the results of our thinking.

Six distinct directions are identified and assigned a color, as show in Fig.3. The six directions are: 


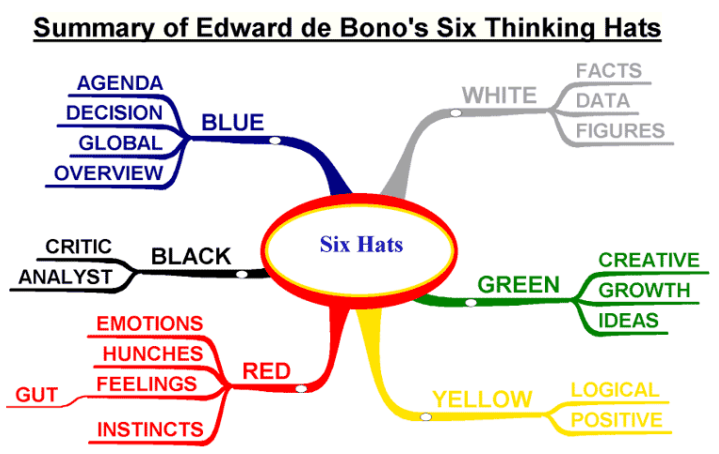

Figure. 3 The Six Thinking Hats

- Managing Blue - what is the subject? what are we thinking about? what is the goal?

- Information White - considering purely what information is available, what are the facts?

- Emotions Red - intuitive or instinctive gut reactions or statements of emotional feeling (but not any justification).

- Discernment Black - logic applied to identifying reasons to be cautious and conservative.

- Optimistic response Yellow - logic applied to identifying benefits, seeking harmony.

- Creativity Green - statements of provocation and investigation, seeing where a thought goes.

Coloured hats are used as metaphors for each direction. Switching to a direction is symbolized by the act of putting on a coloured hat, either literally or metaphorically. These metaphors allow for a more complete and elaborate segregation of the thinking directions. The six thinking hats indicate problems and solutions about an idea the thinker may come up with.

For instance, a meeting may be called to review teaching problems existing in the "Modern Machining Technology" and to develop a solution for the problem. The Six Thinking Hats method could then be used in a sequence to first of all explore the problem, then develop a set of solutions, and to finally choose a solution through critical examination of the solution set.

So the meeting may start with everyone assuming the Blue hat to discuss how the meeting will be conducted and to develop the goals and objectives. The discussion may then move to Red hat thinking in order to collect opinions and reactions to the problem. This phase may also be used to develop constraints for the actual solution such as who will be affected by the problem and/or solutions. Next the discussion may move to the (Yellow then) Green hat in order to generate ideas and possible solutions. Next the discussion may move between White hat thinking as part of developing information and Black hat thinking to develop criticisms of the solution set.

Because everyone is focused on a particular approach at any one time, the group tends to be more collaborative than if one person is reacting emotionally (Red hat) while another person is trying to be objective (White hat) and still another person is being critical of the points which emerge from the discussion (Black hat).

\section{The Comparison between the 2 Years before and after PDCA Cycle and Six Thinking Hats}

The teaching reform can make PDCA cycle and Six Thinking Hats get effective implementation in all the teaching links and make the teaching effectiveness be improved gradually.

Heretofore, we have conducted the teaching of Modern Machining Technology in two semesters in 2013-2014 and 2014-2015. Against the shortage existing in teaching links in 2013-2014, we conduct reform and apply PDCA and Six Thinking Hats application in teaching work in 2014-2015, we have 
achieved remarkable results. Table 1 is the test scores of Modern Machining Technology in 2013-2014. It can be seen from the table that the fraction distribution is the normal distribution and the majority of grades distributes in the range of 70-80 and 80-90, but there is no full mark and failing grade.

The average score is 82.03. Table 2 is the statistical analysis of the test scores of Modern Machining Technology in the first semester of 2014-2015. It can be seen from Table 2 that fraction distribution moves towards the high score range, where the ratio of excellent grades rises from $9.09 \%$ in 2013 to $29 \%$ in 2014 , and there are two full marks, with the average test score of 86.8 , where the average score increases by 4.77 points in 2013-2014.

Table 1 The test scores of Modern Machining Technology in 2013-2014

\begin{tabular}{|c|c|c|c|c|c|}
\hline Score & $<60$ & $60-69$ & $70-79$ & $80-89$ & $90-100$ \\
\hline $\begin{array}{c}\text { Number of } \\
\text { people }\end{array}$ & 0 & 9 & 77 & 184 & 27 \\
\hline Proportion & $0 \%$ & $3.03 \%$ & $25.92 \%$ & $61.95 \%$ & $9.09 \%$ \\
\hline Top score & 96 & Minimum scores & 62 & Average score & 82.03 \\
\hline
\end{tabular}

Table 2 The test scores of Modern Machining Technology in 2014-2015

\begin{tabular}{|c|c|c|c|c|c|}
\hline Score & $<60$ & $60-69$ & $70-79$ & $80-89$ & $90-100$ \\
\hline $\begin{array}{c}\text { Number of } \\
\text { people }\end{array}$ & 0 & 1 & 7 & 224 & 95 \\
\hline Proportion & $0 \%$ & $0.4 \%$ & $2.1 \%$ & $68.5 \%$ & $29 \%$ \\
\hline Top score & 100 & $\begin{array}{c}\text { Minimum } \\
\text { scores }\end{array}$ & 71 & Average score & 86.8 \\
\hline
\end{tabular}

\section{Conclusion}

This paper analyzes the general problems existing in teaching Modern Machining Technology and makes a useful exploration of the PDCA cycle and Six Thinking Hats for Modern Machining Technology Teaching. After nearly a year of teaching experiments, it shows that PDCA cycle and Six Thinking Hats for Modern Machining Technology Reform is feasible; as the introduction of the PDCA cycle and Six Thinking Hats, the quality of Modern Machining Technology teaching has been greatly improved, solving the problems of unsatisfactory teaching effect due to the lack of the class and too scattered and broad teaching materials, which has great practical significance and referential value.

\section{References}

[1] D.W. Zuo, Modern Machining Technology, third ed., BeiHang Press, Beijing, 2013.

[2] X.Y. Si, Application of PDCA cycle in quality management, China Inspection and Quarantine. 6(2004) 35-36.

[3] X. Wang, Application of PDCA circulation in performance appraisal, China Quality Num, 6(2003) $12-13$.

[4] E. Lodgaard, I. Gamme, K. E. Aasland, Success factors for PDCA as continuous improvement method in product development, Springer, 397(2013) 645-652.

[5] H. Wang, Y. Chang, W.S. Che, Application of PDCA-cycle on the management of critical values reporting, Advanced Materials Research. 712-715(2013)3203-3320. 
[6] L.S. Chone, L.T. Heng. Engaging electrical engineering students in oral discussions through Six Thinking Hats in Problem Based Learning, In: 2010 2nd International Congress on Engineering Education: Transforming Engineering Education to Produce Quality Engineers, ICEED2010, IEEE Computer Society, New York, 2010, pp.240 - 244.

[7] D.B. Edward. Six Thinking Hats: An Essential Approach to Business Management, Little, Brown \& Company, New York, 1985.

[8] E. Chikuni, O. I. Okoro, U. B. Akuru, A multi-strategy approach to improve the performance of electrical power engineering students, In: 2013 IEEE 5th International Conference on Engineering Education: Aligning Engineering Education with Industrial Needs for Nation Development, ICEED 2013 , Institute of Electrical and Electronics Engineers Inc., New York, 2014, pp.32 - 36.

[9] F. Paraskeva, A. Chatziiliou, A. Alexiou, Arguing to learn and learning to argue in second life, In: 2013 3rd International Conference on Innovative Computing Technology, INTECH 2013, IEEE Computer Society, New York, 2013, pp.205-207.

[10] Z. Zenko, B. Rosi, M. Mulej, General Systems Theory Completed Up by Dialectical Systems Theory, Systems Research and Behavioral Science. 30(2013) 637-645 